\title{
Continuous juice concentration by integrating forward osmosis with membrane distillation using potassium sorbate preservative as a draw solute
}

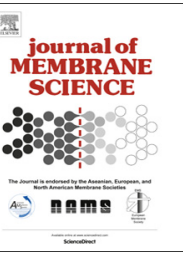

\author{
Xiaochan $\mathrm{An}^{\mathrm{a}, \mathrm{b}, \mathrm{c}}$, Yunxia $\mathrm{Hu}^{\mathrm{a}, *}$, Ning Wang ${ }^{\mathrm{b}}$, Zongyao Zhou ${ }^{\mathrm{a}, \mathrm{b}, \mathrm{c}}$, Zhongyun Liu ${ }^{\mathrm{b}}$ \\ ${ }^{a}$ State Key Laboratory of Separation Membranes and Membrane Processes, National Center for International Research on Membrane Science and Technology, School of \\ Materials Science and Engineering, Tianjin Polytechnic University, Tianjin 300387, PR China \\ ${ }^{\mathrm{b}}$ CAS Key Laboratory of Coastal Environmental Processes and Ecological Remediation, Yantai Institute of Coastal Zone Research, Chinese Academy of Sciences, Yantai, \\ Shandong Province 264003, PR China \\ ${ }^{\mathrm{c}}$ University of Chinese Academy of Sciences, Beijing 100049, PR China
}

A R T I C L E I N F O

\section{Keywords:}

Forward osmosis

Membrane distillation

Juice concentration

Potassium sorbate

Draw Solution

\begin{abstract}
A B S T R A C T
A green and sustainable technique is desired for juice concentration to increase its shelf life and save the transportation cost. In this study, we investigated an integrated forward osmosis-membrane distillation (FO-MD) process for juice concentration and developed a food preservative potassium sorbate as a renewable draw solute. The upstream FO process was used to concentrate apple juice in ambient operation conditions for preserving juice nutrition and flavor. Potassium sorbate preservative was developed as draw solute to minimize the accumulation of a draw solute in the concentrated juice without interfering juice flavor, and the slow diffusion of potassium sorbate preservative across the FO membrane to the feed juice concentrate can also prevent the bacterial growth during the concentration process by taking advantage of reverse salt flux. The downstream MD process was used to recover potassium sorbate draw solutes from the FO effluent and maintain the constant draw solute concentration for achieving stable water flux of FO membranes. Thin-film composite (TFC) polyamide membranes and poly (vinylidene fluoride-co-hexafluoropropylene) (PVDF-HFP) electrospun nanofibrous membranes were fabricated and employed in the FO and MD processes, respectively. Results illustrate that the integrated FO-MD process presents a synergistic flux balancing behavior and achieves a constant water flux for both FO and MD membranes. The FO-MD process was able to continuously concentrate apple juice over longterm bench-scale operation. Importantly, the concentrated apple juice has almost no loss in nutrition and also has very low amount of potassium sorbate $(0.45 \mathrm{~g} / \mathrm{L})$ far below the required maximum level in food industry $(1.00 \mathrm{~g} / \mathrm{L})$. Our work provides a food preservative potassium sorbate draw solute facilitated FO-MD process for juice concentration, which may have practical application potentials in the food processing.
\end{abstract}

\section{Introduction}

Juices are nutrition-rich products for our daily life, which contain vitamins, minerals, and other beneficial constituents for human health $[1,2]$. To increase shelf life and save storage and transportation costs, commercial juices are generally concentrated from raw juices by removing water [3-5]. To date, multi-stage vacuum evaporation and freezing techniques have been widely used for juice concentration [6]. Nevertheless, both techniques are energy-intensive and also bear negative impacts on juice quality [7]. In comparison, the membrane processes such as nanofiltration (NF), and reverse osmosis (RO), present energy-efficient advantages for juice concentration. However, both of them have to be operated under high pressure resulting in severe membrane fouling, and obtains a limited low concentration final juice
[2].

Currently, forward osmosis (FO) has been worked as an emerging membrane technology for fruit juice concentration [8,9]. Although FO has many advantages such as low operation pressure, ambient operation temperature, less membrane fouling, and potential high concentration products, FO is a dilution process and the lack of suitable technology to re-concentrate draw solution limits the widespread application of FO. To achieve a stable water flux, it is critical to provide a constant draw solution concentration during the FO process. Nanofiltration (NF) and reverse osmosis (RO) have been explored to integrate with the FO process for the concentration of draw solutions [10-13], but, they could not be used to concentrate high osmotic draw solutions due to the limit of operation pressure.

Membrane distillation (MD), which is driven by vapor pressure

\footnotetext{
* Corresponding author.

E-mail address: yunxiahu@yic.ac.cn (Y. Hu).
} 


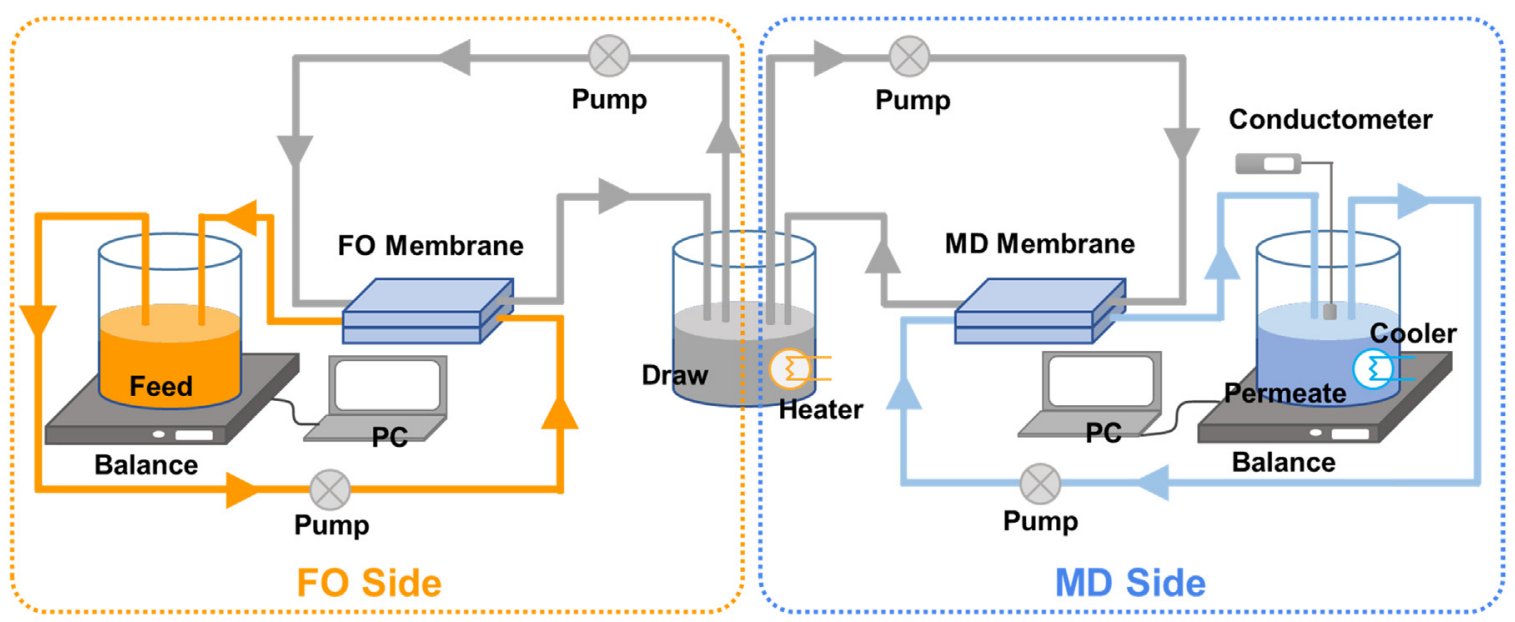

Fig. 1. Schematic diagram of the forward osmosis (FO) - membrane distillation (MD) integrated system.

gradient across a hydrophobic membrane [14], has been integrated with FO to concentrate the diluted draw solutions $[15,16]$. During the operation of FO-MD integrated system, the feed solution is concentrated by the FO process while the diluted draw solution is simultaneously concentrated through the MD process. The integrated FO-MD process combines the advantages of both processes to produces concentrated feed product and draw solution, apart from high-quality water recovery from the draw solution, which has been earlier applied for protein concentration [17], dye wastewater treatment [18], urine treatment [19] and water recovery from sewer mining [16] and oil wastewater [20]. However, to our best knowledge, no study has been reported on juice concentration via an integrated FO-MD system.

Another challenge for juice concentration is the lack of a suitable draw solution with good stability, low price, nontoxicity and minimal reverse salt permeation, favoring both $\mathrm{FO}$ and MD processes. In the past few years, inorganic salt (e.g., $\mathrm{NaCl}, \mathrm{MgCl}_{2}$ ) was mostly studied as draw solutes to provide a osmotic driving force for the suitable water flux also results in accumulation of the draw solute in the final juice products $[8,21]$. In addition, syrup, amino acid and gluconate salts were used as draw solutes because of their high osmotic pressure and high recovery $[22,23]$. But these nutrition-rich draw solutes increased the possibility of membrane fouling by breeding microorganisms. Alternatively, food preservatives could be desirable draw solutes for its antiseptic and necessities in food industry. Potassium sorbate, as a preservative and electrolyte [24], has high osmotic pressure, high water solubility and good thermal stability, non-toxicity and relative low viscosity $[25,26]$, exhibiting a great potential as a draw solute for the FO process. As an essential additive, the accumulated potassium sorbate in the concentrated juice by reverse flux, eliminates the need to remove, and can also prevent the bacterial growth in the membrane during the concentration process. In addition, potassium sorbate is a non-volatile solute, which can be easily re-concentrated in MD process for reuse.

Herein, for the first time, we investigated a sustainable integrated membrane process of forward osmosis-membrane distillation (FO-MD) for apple juice concentration and developed a food preservative; potassium sorbate as a novel renewable draw solution. Thin-film composite (TFC) polyamide membrane was fabricated and its performance to concentrate apple juice by FO was investigated. The poly (vinylidene fluoride-co-hexafluoropropylene) (PVDF-HFP) nanofibrous membrane was fabricated based on our previous work [27] and its performance was evaluated in the MD process to concentrate the diluted potassium sorbate draw solution from the FO process. Finally, we investigated the long-term performance of the integrated FO-MD system with apple juice and potassium sorbate solution as feed and draw solution, respectively, and measured the water flux of TFC FO and MD membrane in the integrated system. The nutritional attributes of the apple were analyzed to evaluate the product quality. This work aims to demonstrate the feasibility of the integrated FO-MD system to concentrate apple juice with a novel draw solute of potassium sorbate, thus providing a facile approach of integrated membrane system for fruit juice processing.

\section{Experimental section}

\subsection{Materials and methods}

Potassium sorbate ( $\geq 98.0 \mathrm{wt} \%$ ) was purchased from Ningbo Wang Long Technology Co., Ltd. (abbreviated as Sorb-K). Sodium chloride $(\mathrm{NaCl}, \geq 99.5 \%)$ was acquired from Sino-pharm Chemical Reagent Co., Ltd. 100\% apple juice (Great Lakes Fresh Food and Juice Co., Ltd.) was obtained in the local supermarket. All chemicals and fruit juices were used as received.

The thin-film composite FO membrane was fabricated following our previous work [28] and the polyamide (PA) active layer was formed through the interfacial polarization of m-phenylenediamine (MPD) and trimesoyl chloride (TMC) on top of an PSF-b-PEG ultrafiltration membrane support. Poly (vinylidene fluoride-co-hexafluoropropylene) (PVDF-HFP) nanofibrous membrane was prepared following our previous work [27] and used in the MD process. The detailed experimental conditions of fabricating FO and MD membranes are provided in Supporting information.

\subsection{Osmotic pressure and relative viscosity measurement of different solutes}

The osmotic pressure of potassium sorbate solutions with various concentrations $(0.5-2.0 \mathrm{M})$ were determined by the freezing-point osmometer (Osmopro3250, YASN Limited., UK) upon suitable dilutions. Osmotic pressures of $\mathrm{NaCl}$ solutions were also tested as controls.

The viscosities of potassium sorbate and $\mathrm{NaCl}$ draw solutions with various concentrations $(0.5-2.0 \mathrm{M})$ at $25^{\circ} \mathrm{C}$ were determined using a viscometer under the constant temperature (DVS +, Brookfield, USA).

\subsection{The operation of FO, MD and FO-MD processes}

The FO-MD experiments were operated in a lab-scale integrated FOMD system as shown in Fig. 1. In the FO-MD system, the draw solution channel of the FO process was also the feed channel of the MD process. The feed, draw, and distillate solutions were circulated at the flow rate of $0.5 \mathrm{~L} / \mathrm{min}$ by individual gear pumps (WT3000-1FA, Longer Pump, China). The feed solution temperature was maintained at $25^{\circ} \mathrm{C}$ using a water bath (SDC-6, Ningbo Scientz Bio-Tech CO., LTD, China). The solution of potassium sorbate was maintained at $25 \pm 1{ }^{\circ} \mathrm{C}$ in a heating 
bath (B-260, Shyarong Biochemical Instrument Factory, China). The distillate temperature of MD process was maintained at $20^{\circ} \mathrm{C}$ using a cooling water bath (SDC-6, Ningbo Scientz Biotechnology CO., LTD, China) and was monitored using a digital thermometer. The water fluxes of TFC FO membrane and nanofibrous MD membrane were monitored as weight changes in the feed solution (FO) and distillate solution (MD) using a digital balance (ME3002, Mettler, Switzerland). The conductivity of the draw solution and distillate permeation was measured by conductivity meter (CON2700, Eutech, USA).

The individual MD system was operated with two temperature control system. Feed side was a potassium sorbate aqueous solution maintained at $25-60{ }^{\circ} \mathrm{C}$ in the heating bath. The cold side was DI water maintained at $20^{\circ} \mathrm{C}$ using the cooling water bath.

\subsection{Analytical methods}

Total soluble solids were determined using an Abbe hand-refractometer (WYT, Chengdu Haochuang Co., China) and expressed as ${ }^{\circ}$ Brix. Ascorbic acid in the juice was measured using a standard iodometric titration method. Titratable acidity was measured using titration method [29]. Briefly, juice samples were titrated with $0.1 \mathrm{M} \mathrm{NaOH}$ to pH 8.2 and quantified as weight percentage of malic acid. Trace concentration of potassium sorbate in the juice solution was measured using a UV-vis spectrophotometer (TU-1810, PERSEE, China) at $255 \mathrm{~nm}$ [30].

\section{Results and discussion}

\subsection{Characterization of potassium sorbate solution as draw solution}

The physicochemical properties of a draw solute, such as molecular weight, water solubility, the $\mathrm{pH}$ and viscosity, are important parameters affecting the performance of TFC FO membrane [31]. Theoretically, the compounds with high molecular weight and high water solubility are potential candidates as effective draw solutes, because the high molecular weight of draw solutes is generally beneficial to achieve a lower reverse solute flux for the FO membrane, whereas the high water solubility of draw solutes helps to obtain a high osmotic pressure with a high molarity of the solute in water [32]. Table 1 shows that potassium sorbate has a much higher molecular weight of $160.22 \mathrm{~g} / \mathrm{mol}$ than $58.44 \mathrm{~g} / \mathrm{mol}$ of the widely used draw solute $\mathrm{NaCl}$, indicating a potential low reverse salt flux of TFC FO membrane when using potassium sorbate as a draw solute, because a large molecule can be rejected by TFC FO membrane. The water solubility of potassium sorbate is $0.676 \mathrm{~g} / \mathrm{g}$, much higher than $0.366 \mathrm{~g} / \mathrm{g}$ of $\mathrm{NaCl}$. In addition, the $\mathrm{pH}$ of potassium sorbate solution is 7.3, favorable for the long-term operation of TFC polyamide membrane.

Viscosity of draw solutions can cause severe concentration polarization in the FO membrane, thereby reducing the water flux. As shown in Fig. 2, potassium sorbate solution shows a comparable low viscosity of $3.57 \mathrm{cP}$ at concentrations under $1.0 \mathrm{M}$, but increases remarkably to $4.92 \mathrm{cP}$ when its concentration further increases to $2.0 \mathrm{M}$. Although the viscosity of potassium sorbate solution is higher than that of $\mathrm{NaCl}$ solution under the same concentration, it is still far below $45 \mathrm{cP}$ of the reported large electrolytes [18] used as draw solutes during the FO process.

The osmotic pressure of a draw solute is the most important parameter to determine its potential application in the FO process. Potassium sorbate solution presents a reasonable high osmotic pressure and increases its osmotic pressure linearly with its molar concentration, as does $\mathrm{NaCl}$ solution. At $2.0 \mathrm{M}$ concentration, the osmotic pressure of potassium sorbate solution is $46 \mathrm{bar}$, comparable with $45 \mathrm{bar}$ of the reported poly(acrylic acid) sodium salt [18], although it is lower than 93 bar of $\mathrm{NaCl}$ solution at the same concentration.

Therefore, potassium sorbate shows good potential as a draw solute since it exhibits appropriate solution properties including non-toxicity, high water solubility, suitable molecular size, relative high osmotic pressure and low viscosity [25,26]. More importantly, potassium sorbate has been widely used as a food preservative in juice and does not affect the flavor of juice, as does salty $\mathrm{NaCl}$.

\subsection{The water flux and reverse salt flux of TFC FO membrane using potassium sorbate draw solution}

The fabricated TFC polyamide membrane has a dense polyamide selective layer formed through the interfacial polarization of MPD and TMC on top of the porous polysulfone-block-polyethylene glycol (PSFb-PEG) membrane support. The characteristic ridge-valley morphology was observed on TFC surfaces (Fig. 3a), and the thickness of active layer was approximately $320 \mathrm{~nm}$ (Fig. 3c). The (PSF-b-PEG) membrane support has large porous finger-like structure with great potential to decrease water and salt transport resistance and thus reduce Internal Concentration Polarization. Importantly, the fabricated TFC polyamide membranes were measured to have a relative high water permeability coefficient $A$ of $1.76 \mathrm{LMH} / \mathrm{bar}$, a low $\mathrm{NaCl}$ permeability coefficient $B$ of $0.09 \mathrm{LMH}$ and a structure parameter $S$ of $370 \mu \mathrm{m}$, having the higher permeability-selectivity performance $\left(A / B, 19.6 \mathrm{bar}^{-1}\right)$ than $6-13 \mathrm{bar}^{-1}$ of most reported TFC FO membranes [33-35]. In addition, the high performance TFC membrane is important to ensure less reverse salt accumulation in the concentrated product.

Potassium sorbate was used as a draw solute to investigate the performance of TFC polyamide membrane under the AL-FS (active layer facing to feed solution) operation mode and AL-DS (active layer facing to draw solution) operation mode when DI water was used as a feed solution. Results shown in Fig. 4 illustrate that the water flux of TFC polyamide membrane increased with the increasing concentration of potassium sorbate draw solution from $0.5 \mathrm{M}$ to $2.0 \mathrm{M}$, when operating under both of AL-FS and AL-DS modes. The water flux of TFC membrane was much higher when operating under the AL-DS mode than under the AL-FS mode, as did the water flux of TFC membrane when $\mathrm{NaCl}$ was used as a draw solution. For example, the water flux of TFC membrane was $28.65 \mathrm{LMH}$ under the AL-DS mode when $2.0 \mathrm{M}$ potassium sorbate solution was used as a draw solution, 2-fold increase compared with $14.40 \mathrm{LMH}$ of its water flux under the AL-FS mode. It is a characteristic phenomenon for TFC polyamide membrane due to its severe internal concentration polarization when operating in the AL-FS mode [36]. While, with potassium sorbate used as a draw solute, the water flux of TFC membrane was significantly lower than that with the same concentration of $\mathrm{NaCl}$ draw solution, owing to a much lower osmotic pressure difference between the feed and potassium sorbate solution. When $2.0 \mathrm{M}$ potassium sorbate solution was used as a draw solution, the reverse salt flux of TFC membrane was $0.57 \mathrm{gMH}$ and 1.01 gMH during the AL-FS and AL-DS modes respectively, approximately 10 times lower than the corresponding $5.21 \mathrm{gMH}$ and $11.35 \mathrm{gMH}$ when

Table 1

Physicochemical properties of potassium sorbate and sodium chloride.

\begin{tabular}{|c|c|c|c|c|c|}
\hline Compound & Chemical structure & Abbreviation & Molecular weight $\mathrm{g} / \mathrm{mol}$ & Water solubility (g/g water, $25^{\circ} \mathrm{C}$ ) & Solution $\mathrm{pH}\left(1 \mathrm{M}, 25^{\circ} \mathrm{C}\right)$ \\
\hline Potassium Sorbate & & Sorb-K & 150.22 & 0.676 & 7.3 \\
\hline Sodium Chloride & $\mathrm{Na}^{+} \mathrm{Cl}^{-}$ & $\mathrm{NaCl}$ & 58.44 & 0.366 & 7.0 \\
\hline
\end{tabular}




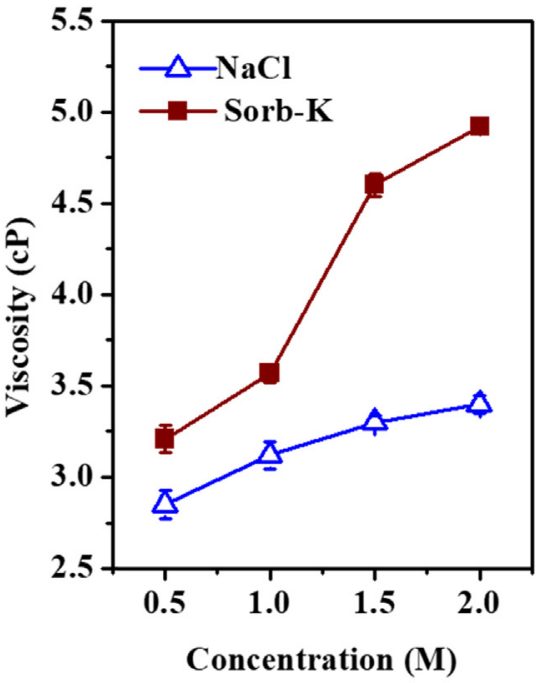

a

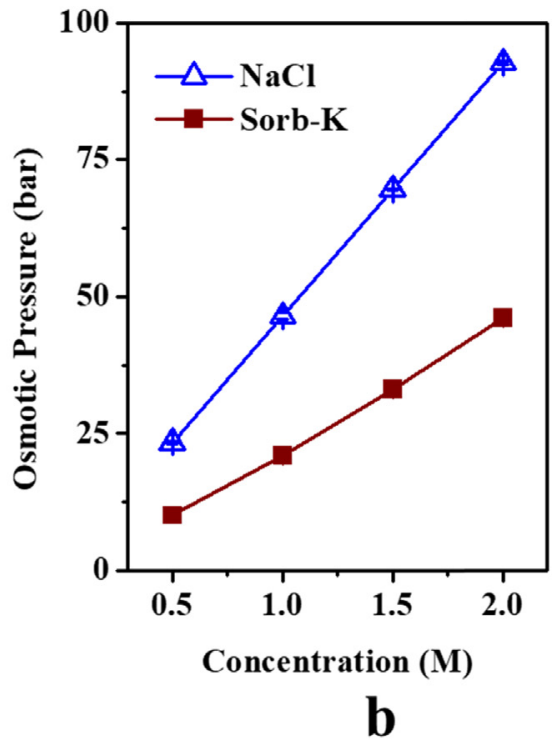

Fig. 2. The viscosities (a) and osmotic pressures (b) of potassium sorbate and $\mathrm{NaCl}$ solutions with various concentrations in water at $25^{\circ} \mathrm{C}$.

2.0 M sodium chloride solution was used as a draw solution.

Specific salt flux $\left(\mathrm{J}_{\mathrm{W}} / \mathrm{J}_{\mathrm{S}}, \mathrm{g} / \mathrm{L}\right)$ is used to determine the mass of draw solute loss from the draw solution when one liter of water permeates through the membrane to draw solution, and thus to compare the performance of FO membrane with different draw solutes. Fig. 4c presents that the TFC polyamide membrane exhibited a significant lower specific salt flux when using potassium sorbate as draw solution, as compared to $\mathrm{NaCl}$ solution in AL-FS and AL-DS modes. With $2.0 \mathrm{M}$ potassium sorbate draw solution, the specific salt flux of TFC polyamide membrane was $0.04 \mathrm{~g} / \mathrm{L}$ operating under both AL-FS and AL-DS modes, 5-6 times lower than the corresponding $0.20 \mathrm{~g} / \mathrm{L}$ and $0.26 \mathrm{~g} / \mathrm{L}$ when $2.0 \mathrm{M} \mathrm{NaCl}$ solution was used as a draw solution. Therefore, potassium sorbate exhibits very low salt leakage across the TFC polyamide membrane because of its relative large molecular size in comparison with sodium chloride.

Commercially available $100 \%$ apple juice was used as a feed solution and potassium sorbate as draw solution to investigate the performance of TFC polyamide membrane with real system. Fig. 5a shows that when potassium sorbate draw concentration increased from $1.5 \mathrm{M}$ to $2.0 \mathrm{M}$, the water flux increased from 4.90 to $5.71 \mathrm{LMH}$ in AL-FS operation, due to the severe membrane fouling induced by viscous apple juice leading to much low water flux in comparison with that when DI water being used as feed solution. Fig. 5b shows that with 2.0 M potassium sorbate as a draw solution, the water fluxes under ALFS and AL-DS modes were very close to $5 \mathrm{LMH}$, which is not typical with higher water flux when operating in the AL-DS mode than in the AL-FS mode when DI water was used as a feed solution. It may because of the severe membrane fouling and internal concentration polarization
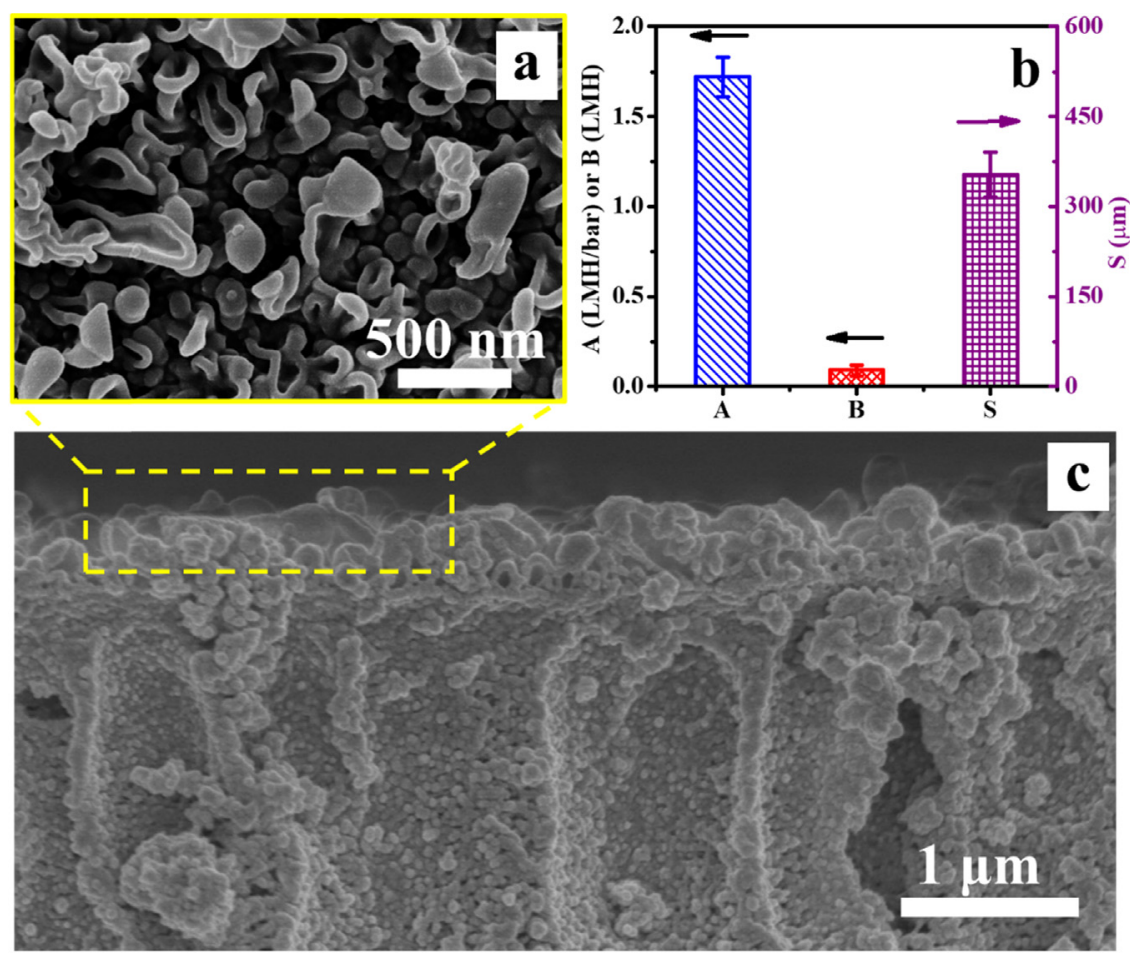

Fig. 3. Surface (a) and cross-sectional (c) morphologies of TFC polyamide membrane, and its intrinsic transport parameter including water permeability coefficient $A$, $\mathrm{NaCl}$ permeability coefficient $B$ and structural parameter $S$ (b). TFC polyamide membrane shows characteristic fruitful ridge-valley morphologies of polyamide selective layer with approximately $320 \mathrm{~nm}$ thickness, and large porous finger-like structure of the PSF-b-PEG membrane support. 

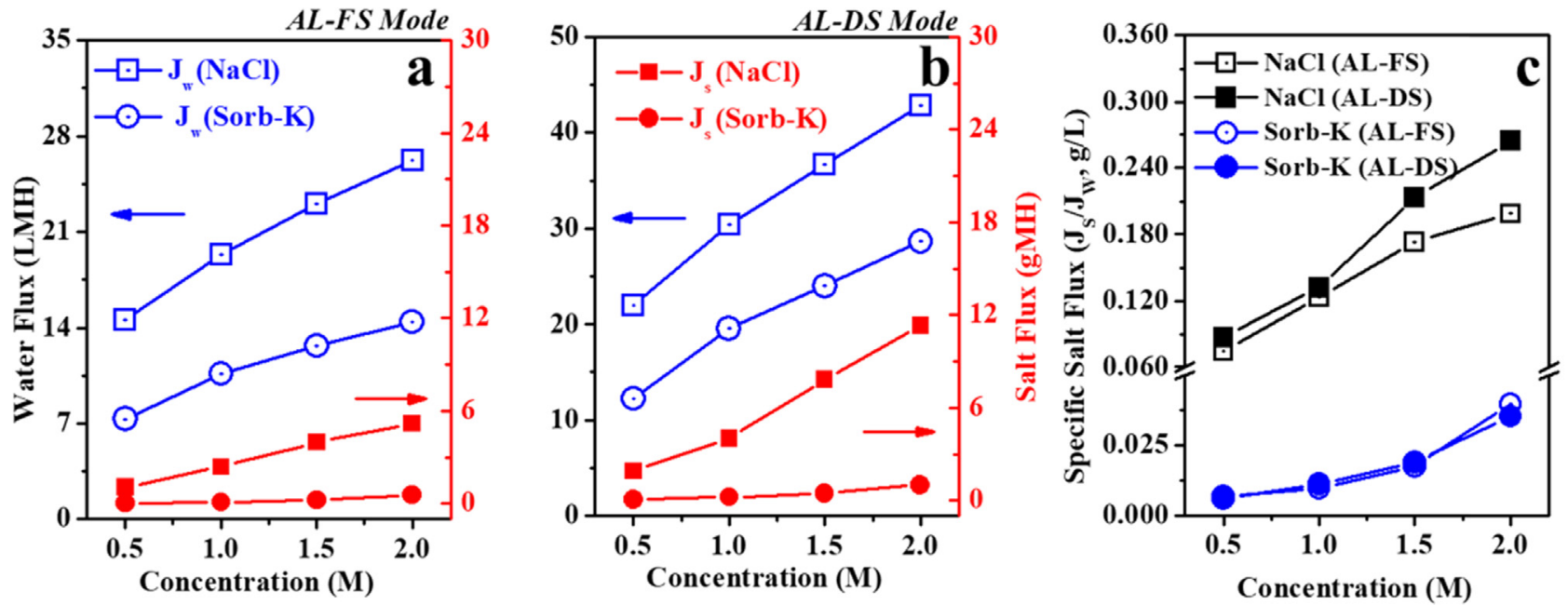

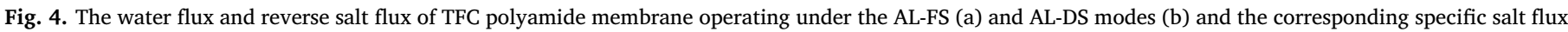
(c) with various concentrations of potassium sorbate and sodium chloride solutions as draw solutions. DI water was used as feed solution.
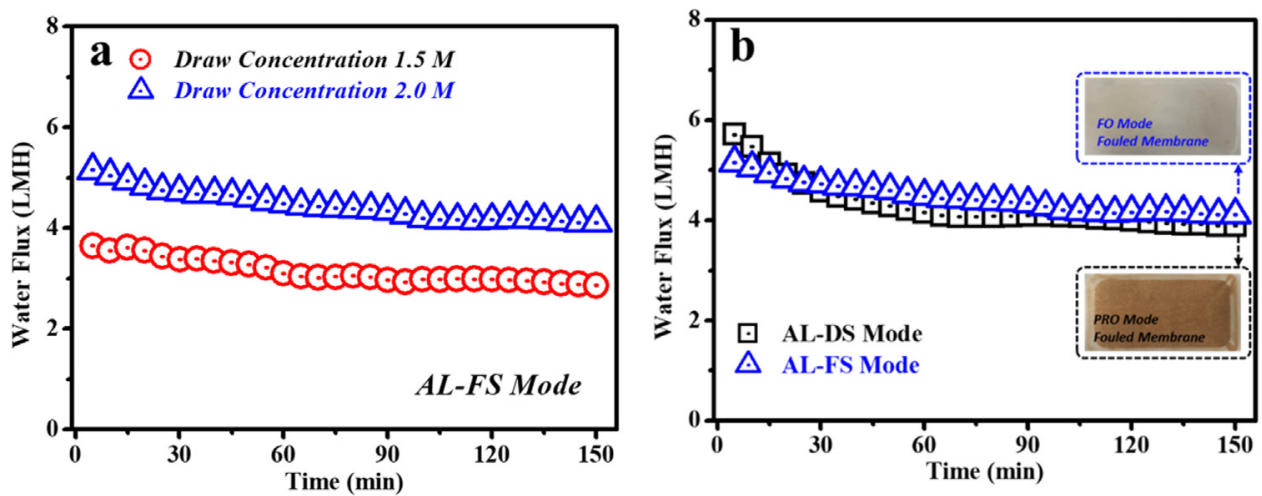

Fig. 5. The water flux of TFC polyamide membrane during the juice concentration when using $1.5 \mathrm{M}$ and $2.0 \mathrm{M}$ potassium sorbate draw solutions operating under the AL-FS mode (a) and when using $2.0 \mathrm{M}$ potassium sorbate draw solution operating under the ALFS and AL-DS modes (b). The optical images of TFC membranes after operating under the FO and PRO modes are inserted in (b). Commercial apple juice was used as a feed solution.
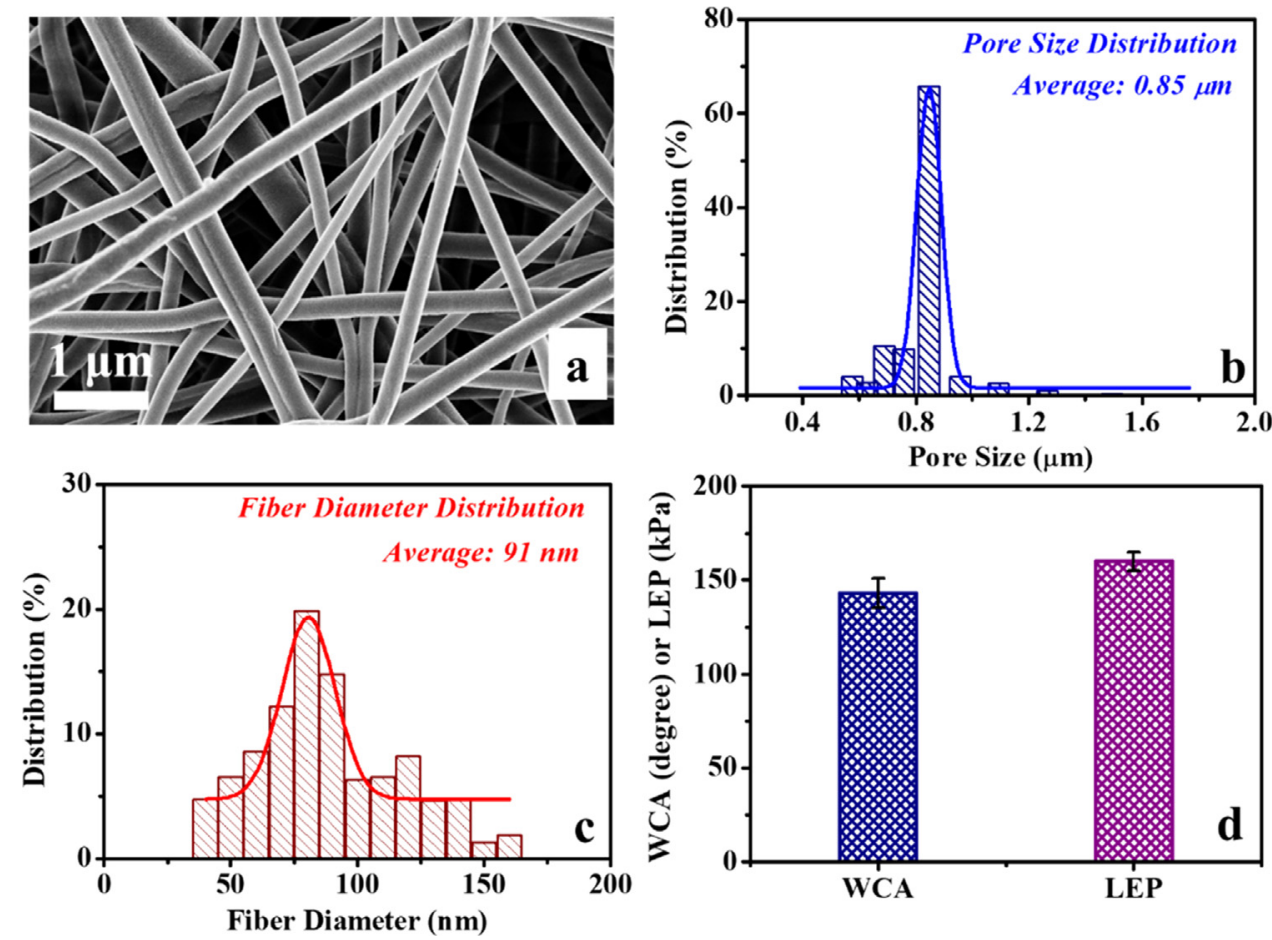

Fig. 6. Characterization of PVDF-HFP electrospun nanofibrous membrane including surface morphology (a), pore size distribution (pore diameter distribution) (b), fiber diameter distribution (c), and water contact angle (WCA) and liquid entry pressure (LEP) (d). 

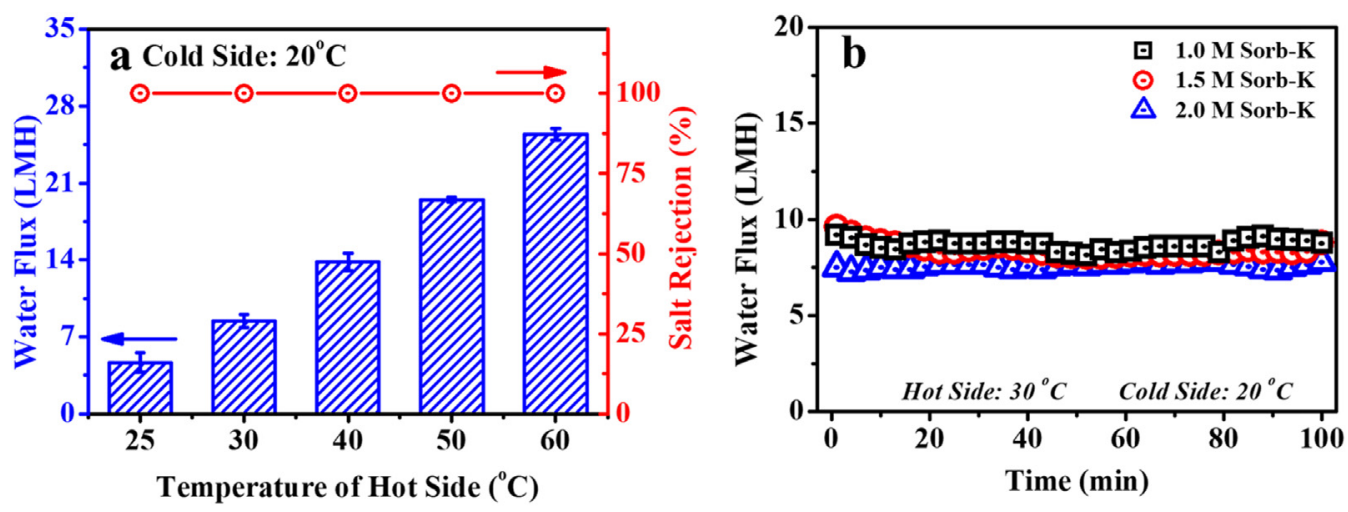

Fig. 7. The water flux of PVDF-HFP nanofibrous membrane in the MD process operating under various hot side temperatures (a) and with various concentrations of potassium sorbate solution as feed solutions (b) under the temperature difference of $10^{\circ} \mathrm{C}$.
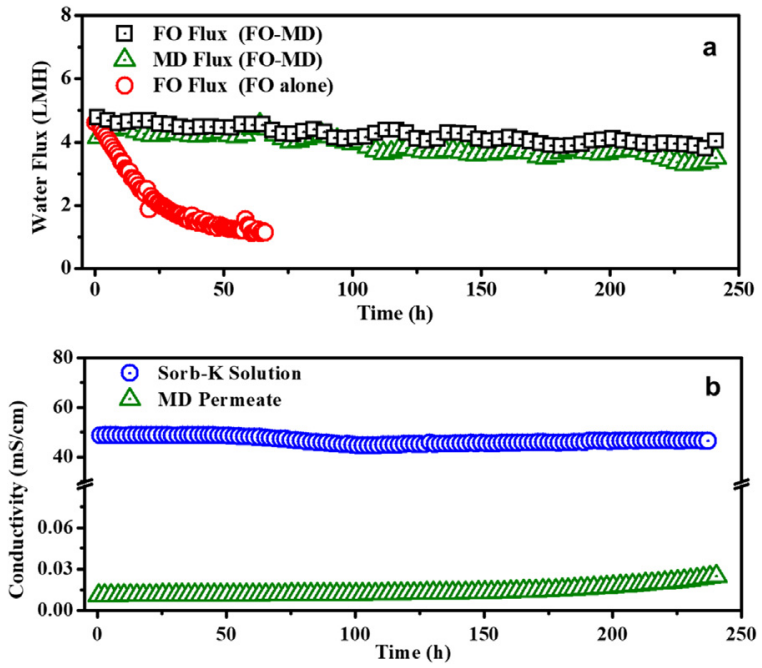

Fig. 8. 100\% apple juice was concentrated using the integrated FO - MD system and an individual FO system: the water fluxes (a) of FO process and MD process in the integrated FO-MD system and also in an individual FO system; and the conductivities (b) of potassium sorbate draw solution and MD permeate in the integrated FO-MD system.

Table 2

Physicochemical properties of the pristine juice and concentrated apple juice after $240 \mathrm{~h}$ concentration through the integrated FO-MD system at ambient temperature $\left(25 \pm 1{ }^{\circ} \mathrm{C}\right)$.

\begin{tabular}{lll}
\hline Property & Pristine apple juice & Concentrated apple juice \\
\hline TSS ( $\left.{ }^{\circ} \mathrm{Brix}\right)$ & $10.6 \pm 0.7$ & $45.1 \pm 0.4$ \\
Concentrated times & - & 4.25 \\
Ascorbic acid $(\mathrm{g} / \mathrm{L})$ & $1.1 \pm 0.1$ & $3.9 \pm 0.1$ \\
Titratable acid $(\mathrm{mg} /$ & $0.2 \pm 0.1$ & $0.8 \pm 0.1$ \\
$\quad$ & & $0.45 \pm 0.09$ \\
$\quad$ Potassium sorbate $(\mathrm{g} / \mathrm{L})$ & - & \\
\hline
\end{tabular}

induced by viscous apple juice in the TFC membrane support in the ALDS mode [22]. The optical images of the TFC membrane present a dark brown color due to fouling in the membrane support after the AL-DS mode operation, and a relative light color after the AL-FS mode operation, indicating a more severe membrane fouling occurring in the AL-DS mode than in the AL-FS mode.

Therefore, the AL-FS operation mode was much appropriate for juice concentration to achieve a relative high-water flux and less membrane fouling. In addition, the membrane water flux ( $5 \mathrm{LMH}$ ) here is much higher than the reported water flux (approximately $2 \mathrm{LMH}$ ) of other FO membranes used for apple juice concentration [22]. Because our fabricated TFC membrane exhibits higher permeability-selectivity than the reported commercial TFC membranes from HTI and the $A / B$ value of our fabricated TFC membranes is $19.5 \mathrm{bar}^{-1}$, much higher than $10.11 \mathrm{bar}^{-1}$ of commercial HTI TFC membranes [37].

\subsection{Application of MD to concentrate potassium sorbate draw solution}

The PVDF-HFP electrospun nanofibrous membrane was fabricated for use in the MD process. Fig. 6a finds that PVDF-HFP nanofibrous membrane has typical interconnected porous morphology and an average pore size of $0.85 \mu \mathrm{m}$ (Fig. $6 \mathrm{~b}$ ), comparable with the reported pore size of most MD membranes [38]. Moreover, the PVDF-HFP electrospun nanofibers have an average diameter of $91 \mathrm{~nm}$ (Fig. 6c) and the PVDF-HFP nanofibrous membrane is very hydrophobic having water contact angle (WCA) of $143^{\circ}$, and its liquid entry pressure (LEP) is $160 \mathrm{kPa}$ (Fig. 6b), indicating high anti-wetting property of PVDF-HFP nanofibrous membranes. The effect of temperature difference on the MD performance of PVDF-HFP nanofibrous membranes were investigated. Results shown in Fig. 7a indicates that the water flux of the PVDF-HFP nanofibrous membrane increased linearly with increasing temperature difference and reached $25.4 \pm 0.5 \mathrm{LMH}$ when the temperature difference between the heating solution and cooling solution of the MD system was $40^{\circ} \mathrm{C}$, which is comparable with most of reported nanofibrous MD membranes under similar conditions [39-41]. Besides, the MD membrane exhibited almost $100 \%$ salt rejection since there was no obvious change of conductivity in the permeate solution. Moreover, there was no obvious effect of potassium sorbate concentration on the water flux of PVDF-HFP nanofibrous membrane as shown in Fig. 7b. A relative constant water flux of 7.6 LMH was achieved for all potassium sorbate feed solutions having different concentrations including $1.0 \mathrm{M}$, $1.5 \mathrm{M}$, and $2.0 \mathrm{M}$ during the MD process, when the temperature difference between the heating and cooling solution of the MD systems were $10^{\circ} \mathrm{C}$. Thus, all these results suggest that the PVDF-HFP nanofibrous membrane could achieve a stable and controllable water flux in the MD process to concentrate potassium sorbate solution, providing great potential to integrate with the FO process.

\subsection{The integration of FO and MD system to concentrate apple juice}

To concentrate apple juice and investigate the operation sustainability of the integrated FO-MD system, we used commercial $100 \%$ apple juice as a feed solution and $2.0 \mathrm{M}$ potassium sorbate solution as draw solution in the FO process. Both feed and draw solutions were kept at ambient temperature at $25 \pm 1{ }^{\circ} \mathrm{C}$ during the operation to retain juice nutrition and quality. To match with the water flux ( $~ 5 \mathrm{LMH})$ in the FO process, we adjusted the temperature of distillate side in the MD process at $20 \pm 1{ }^{\circ} \mathrm{C}$ and achieved its water flux in the range of 4 $\mathrm{LMH}$ and $6 \mathrm{LMH}$. Fig. 8a shows that a relative stable water flux 
(approximately $5 \mathrm{LMH}$ ) was achieved in both FO process and MD process during $240 \mathrm{~h}$ operation of the integrated FO-MD system to concentrate apple juice, indicating a stable performance of our fabricated TFC FO membrane and PVDF-HFP nanofibrous membrane. In contrast, individual FO process presented a remarkable water flux decline due to the significant dilution of draw solution during the concentration of apple juice. Potassium sorbate draw solution kept a constant concentration showing a constant conductivity, and the MD permeation solution remained a constant conductivity below $30 \mu \mathrm{S} / \mathrm{cm}$, as shown in Fig. 8b. These results illustrate that the high recovery of potassium sorbate draw solution and high rejection of potassium sorbate during the operation of MD process.

Selected attributes of pristine juice and final product were analyzed and shown in Table 2. The total soluble solid (TSS) increased from $10.6 \pm 0.7^{\circ}$ Brix to $45.1 \pm 0.4^{\circ}$ Brix before and after concentration through the integrated FO-MD system, and thus $100 \%$ commercial apple juice was concentrated by 4.25 folds, which is higher than 2.36 fold of the reported juice concentration through reverse osmosis [6]. Besides, the nutrition in the final concentrated juice including ascorbic acid and titratable acid was also concentrated accordingly. Importantly, the amount of accumulated reverse potassium sorbate in the final concentrated juice was only $0.45 \pm 0.09 \mathrm{~g} / \mathrm{L}$, which was far below the required maximum level in food industry (i.e. $1.0 \mathrm{~g} / \mathrm{L}$ in CODEX STAN 192-1995, Codex Alimentarius Commission). Thus, the potassium sorbate in the final product has no need to remove. Additionally, the gradual addition of small amount of potassium sorbate preservative to the juice concentrate can prevent the bacterial growth during the concentration process. From the attributes analyzed in the processed apple juice, it may be concluded that the concentrated juice obtained from the FO-MD system has almost no loss in these nutrition parameters and has acceptable amounts of potassium sorbate. Moreover, our results suggest that the apple juice could be concentrated to an even higher concentration with the integrated FO-MD system for an extended time, showing considerable advantage of the FO-MD system for juice concentration.

\section{Conclusion}

In this study, we demonstrated the sustainability and stability of an integrated FO-MD system for apple juice concentration. We also developed food preservative potassium sorbate as a practical draw solute in the integrated FO-MD process owing to its high osmotic pressure and suitable molecule size with very low accumulation in the final apple juice product. Importantly, potassium sorbate preservative has a very low reverse salt flux and thus has very low accumulation (far below the regulated maximum level in food industry) in the final concentrated juice, and slow diffusion of potassium sorbate preservative to the feed juice concentrate can also prevent the bacterial growth in the juice during the concentration process. Stable water flux $(\sim 5 \mathrm{LMH})$ was achieved through the integrated FO-MD system during $240 \mathrm{~h}$ operation, indicating a high performance of our fabricated TFC FO and MD membranes with less fouling during the apple juice concentration. A 4.25-fold concentrated apple juice and clean water (conductivity $<25 \mu \mathrm{S} / \mathrm{cm}$ ) were obtained simultaneously to successfully confirm the application of the integrated FO-MD system for juice concentration. Importantly, during the operation of the integrated FOMD system, apple juice feed solution and potassium sorbate draw solution was kept at ambient temperature at $25 \pm 1{ }^{\circ} \mathrm{C}$ to retain juice quality, and the regeneration of constant potassium sorbate draw solution was performed in the MD process with a distillate side at $20 \pm 1{ }^{\circ} \mathrm{C}$, providing cost-effective advantage of the integrated FO-MD system in comparison with the evaporating or freezing methods. Thus, our work develops a sustainable FO-MD integrated system with promising scale-up and practical applications, which is not only for juice concentration but for other food processing and biomolecules concentration. Further scale-up investigation is needed to apply the integrated FO-MD system for industrial juice concentration.

\section{Acknowledgement}

The authors gratefully acknowledge the funding support from National Natural Science Foundation of China (No. 21476249, No. 51708408), Chang-jiang Scholars and Innovative Research Team in the University of Ministry of Education, China (No. IRT-17R80) and The Science and Technology Plans of Tianjin (No.17PTSYJC00060).

\section{Notes}

The authors declare no competing financial interest.

\section{Appendix A. Supporting information}

Supplementary data associated with this article can be found in the online version at doi:10.1016/j.memsci.2018.12.010.

\section{References}

[1] V. Sant'Anna, L.D.F. Marczak, I.C. Tessaro, Membrane concentration of liquid foods by forward osmosis: process and quality view, J. Food Eng. 111 (2012) 483-489.

[2] B. Girard, L.R. Fukumoto, Membrane processing of fruit juices and beverages: a review, Crit. Rev. Biotechnol. 20 (2000) 109-175.

[3] P. Onsekizoglu, K.S. Bahceci, M.J. Acar, Clarification and the concentration of apple juice using membrane processes: a comparative quality assessment, J. Membr. Sci. 352 (2010) 160-165.

[4] S. Gunko, S. Verbych, M. Bryk, N. Hilal, Concentration of apple juice using direct contact membrane distillation, Desalination 190 (2006) 117-124.

[5] D. Mondal, S.K. Nataraj, A.V. Rami Reddy, K.K. Ghara, P. Maiti, S.C. Upadhyay, P.K. Ghosh, Four-fold concentration of sucrose in sugarcane juice through energy efficient forward osmosis using sea bittern as draw solution, RSC Adv. 5 (2015) 17872-17878.

[6] V. Alvarez, S. Alvarez, F.A. Riera, R. Alvarez, Permeate flux prediction in apple juice concentration by reverse osmosis, J. Membr. Sci. 127 (1997) 25-34.

[7] A. Cassano, A. Figoli, A. Tagarelli, G. Sindona, E. Drioli, Integrated membrane process for the production of highly nutritional kiwifruit juice, Desalination 189 (2006) 21-30.

[8] B.R. Babu, N.K. Rastogi, K.S.M.S. Raghavarao, Effect of process parameters on transmembrane flux during direct osmosis, J. Membr. Sci. 280 (2006) 185-194.

[9] C.A. Nayak, N.K. Rastogi, Forward osmosis for the concentration of anthocyanin from Garcinia indica Choisy, Sep. Purif. Technol. 71 (2010) 144-151.

[10] C.H. Tan, H.Y. Ng, A novel hybrid forward osmosis - nanofiltration (FO-NF) process for seawater desalination: draw solution selection and system configuration, Desalin. Water Treat. 13 (2012) 356-361.

[11] O.A. Bamaga, A. Yokochi, B. Zabara, A.S. Babaqi, Hybrid FO/RO desalination system: preliminary assessment of osmotic energy recovery and designs of new FO membrane module configurations, Desalination 268 (2011) 163-169.

[12] S.J. Im, J. Choi, S. Jeong, A. Jang, New concept of pump-less forward osmosis (FO) and low-pressure membrane (LPM) process, Sci. Rep. 7 (2017) 14569.

[13] Q. Long, L. Shen, R. Chen, J. Huang, S. Xiong, Y. Wang, Synthesis and application of organic phosphonate salts as draw solutes in forward osmosis for oil-water separation, Environ. Sci. Technol. 50 (2016) 12022-12029.

[14] L.D. Tijing, J.-S. Choi, S. Lee, S.-H. Kim, H.K. Shon, Recent progress of membrane distillation using electrospun nanofibrous membrane, J. Membr. Sci. 453 (2014) 435-462.

[15] Q. Ge, G. Han, T.S. Chung, Effective, As(III) removal by a multi-charged hydroacid complex draw solute facilitated forward osmosis-membrane distillation (FO-MD) processes, Environ. Sci. Technol. 50 (2016) 2363-2370.

[16] M. Xie, L.D. Nghiem, W.E. Price, M. Elimelech, A forward osmosis-membrane distillation hybrid process for direct sewer mining: system performance and limitations, Environ. Sci. Technol. 47 (2013) 13486-13493.

[17] K.Y. Wang, M.M. Teoh, A. Nugroho, T.-S. Chung, Integrated forward osmosis-membrane distillation (FO-MD) hybrid system for the concentration of protein solutions, Chem. Eng. Sci. 66 (2011) 2421-2430.

[18] Q. Ge, P. Wang, C. Wan, T.S. Chung, Polyelectrolyte-promoted forward osmosismembrane distillation (FO-MD) hybrid process for dye wastewater treatment, Environ. Sci. Technol. 46 (2012) 6236-6243.

[19] Q. Liu, C. Liu, L. Zhao, W. Ma, H. Liu, J. Ma, Integrated forward osmosis-membrane distillation process for human urine treatment, Water Res. 91 (2016) 45-54.

[20] S. Zhang, P. Wang, X. Fu, T.S. Chung, Sustainable water recovery from oily wastewater via forward osmosis-membrane distillation (FO-MD), Water Res. 52 (2014) $112-121$

[21] E.M. Garcia-Castello, J.R. McCutcheon, M. Elimelech, Performance evaluation of sucrose concentration using forward osmosis, J. Membr. Sci. 338 (2009) 61-66.

[22] Q. Long, G. Qi, Y. Wang, Evaluation of renewable gluconate salts as draw solutes in forward osmosis process, ACS Sustain. Chem. Eng. 4 (2016) 85-93.

[23] K. Lutchmiah, L. Lauber, K. Roest, D.J.H. Harmsen, J.W. Post, L.C. Rietveld, J.B. van 
Lier, E.R. Cornelissen, Zwitterions as alternative draw solutions in forward osmosis for application in wastewater reclamation, J. Membr. Sci. 460 (2014) 82-90.

[24] X.L. Shen, J.M. Wu, Y. Chen, G. Zhao, Antimicrobial and physical properties of sweet potato starch films incorporated with potassium sorbate or chitosan, Food Hydrocoll. 24 (2010) 285-290.

[25] M.C. Robach, F.J. Ivey, Antimicrobial efficacy of a potassium sorbate dip on freshly processed poultry, J. Food Prot. 41 (1978) 284-288.

[26] Scientific Opinion on the re-evaluation of sorbic acid (E 200), potassium sorbate (E 202) and calcium sorbate (E 203) as food additives, EFSA Journal, 13, 2015, p 4144.

[27] X. An, Z. Liu, Y. Hu, Amphiphobic surface modification of electrospun nanofibrous membranes for anti-wetting performance in membrane distillation, Desalination 432 (2018) 23-31.

[28] N. Wang, T. Wang, Y. Hu, Tailoring membrane surface properties and ultrafiltration performances via the self-assembly of polyethylene glycol-block-polysulfone-blockpolyethylene glycol block copolymer upon thermal and solvent annealing, ACS Appl. Mater. Interfaces 9 (2017) 31018-31030.

[29] S.P. Verma, B. Sarkar, Analysis of flux decline during ultrafiltration of apple juice in a batch cell, Food Bioprod. Process. 94 (2015) 147-157.

[30] H.M. Pylypiw, M.T. Grether, Rapid high-performance liquid chromatography method for the analysis of sodium benzoate and potassium sorbate in foods, J. Chromatogr. A 883 (2000) 299-304.

[31] Q. Ge, M. Ling, T.-S. Chung, Draw solutions for forward osmosis processes: developments, challenges, and prospects for the future, J. Membr. Sci. 442 (2013) $225-237$.

[32] L. Chekli, S. Phuntsho, H.K. Shon, S. Vigneswaran, J. Kandasamy, A. Chanan, A review of draw solutes in forward osmosis process and their use in modern applications, Desalin. Water Treat. 43 (2012) 167-184.
[33] A. Tiraferri, N.Y. Yip, A.P. Straub, S. Romero-Vargas Castrillon, M. Elimelech, A method for the simultaneous determination of transport and structural parameters of forward osmosis membranes, J. Membr. Sci. 444 (2013) 523-538.

[34] P.H. Duong, S. Chisca, P.Y. Hong, H. Cheng, S.P. Nunes, T.S. Chung, Hydroxyl functionalized polytriazole-co-polyoxadiazole as substrates for forward osmosis membranes, ACS Appl. Mater. Interfaces 7 (2015) 3960-3973.

[35] L. Xu, J. Xu, B. Shan, X. Wang, C. Gao, Novel thin-film composite membranes via manipulating the synergistic interaction of dopamine and $\mathrm{m}$-phenylenediamine for highly efficient forward osmosis desalination, J. Mater. Chem. A 5 (2017) 7920-7932.

[36] S. Zhao, L. Zou, C.Y. Tang, D. Mulcahy, Recent developments in forward osmosis: opportunities and challenges, J. Membr. Sci. 396 (2012) 1-21.

[37] M. Xie, E. Bar-Zeev, S.M. Hashmi, L.D. Nghiem, M. Elimelech, Role of reverse divalent cation diffusion in forward osmosis biofouling, Environ. Sci. Technol. 49 (2015) 13222-13229.

[38] M.S. El-Bourawi, Z. Ding, R. Ma, M. Khayet, A framework for better understanding membrane distillation separation process, J. Membr. Sci. 285 (2006) 4-29.

[39] Y. Liao, R. Wang, M. Tian, C. Qiu, A.G. Fane, Fabrication of polyvinylidene fluoride (PVDF) nanofiber membranes by electro-spinning for direct contact membrane distillation, J. Membr. Sci. 425-426 (2013) 30-39.

[40] B.S. Lalia, E. Guillen-Burrieza, H.A. Arafat, R. Hashaikeh, Fabrication and characterization of polyvinylidenefluoride-co-hexafluoropropylene (PVDF-HFP) electrospun membranes for direct contact membrane distillation, J. Membr. Sci. 428 (2013) 104-115.

[41] M. Yao, Y.C. Woo, L.D. Tijing, W.-G. Shim, J.-S. Choi, S.-H. Kim, H.K. Shon, Effect of heat-press conditions on electrospun membranes for desalination by direct contact membrane distillation, Desalination 378 (2016) 80-91. 